\title{
Multifunction Grid Connected System using Partial Power Converter
}

\author{
Priyadarshini.S.A ${ }^{1}$, Vigneshwaran. $P^{2}$ \\ Assistant Professor, EEE Department, K. Ramakrishnan College of Engineering, Tiruchirappalli, India ${ }^{1,2}$
}

\begin{abstract}
This paper presents a multifunction grid connected system using partial power converter .The proposed micro inverter employs a two-stage topology with active- clamped current-fed push pull converter cascaded with a full bridge inverter. This system can operate in grid connected mode to feed power to the grid with a programmable power factor. This presents a multi-loop control scheme with programmable capability for achieving multiple functions. This implements a partial power converter for DC-DC converter stage. In addition, the proposed control scheme embedded a multi-module parallel capability that multiple MI modules can be paralleled to enlarge the capacity with autonomous control in all operation modes.
\end{abstract}

Keywords: Autonomous control of inverter, active-clamped current-fed push-pull converter, zero feeding power

\section{INTRODUCTION}

Micro Inverter (MI) schemes using a single inverter for each Photo Voltaic (PV) module have a number of advantages over the string inverter: (i)They are free from the issue of shading;(ii)Maximum Power Point Tracking (MPPT) can be implemented for individual Photo Voltaic (PV) modules to maximize efficiency; and(iii)Installation and maintenance are simple and easy. Each micro inverter harvests optimum power by performing Maximum Power Point Tracking (MPPT) for its connected module. The fact that PV power fluctuates with exposure to sunlight means that PV inverters and MIs are designed primarily for grid connected applications in which output current is controlled and output voltage is supported by the grid. In some applications, there are strict regulations against the injection of electrical power generated by solar systems into general energy grid, such that PV power can be utilized only by installer. This necessitates the inclusion of control devices to communicate with the MIs to override MI modules for zero power feeding application.
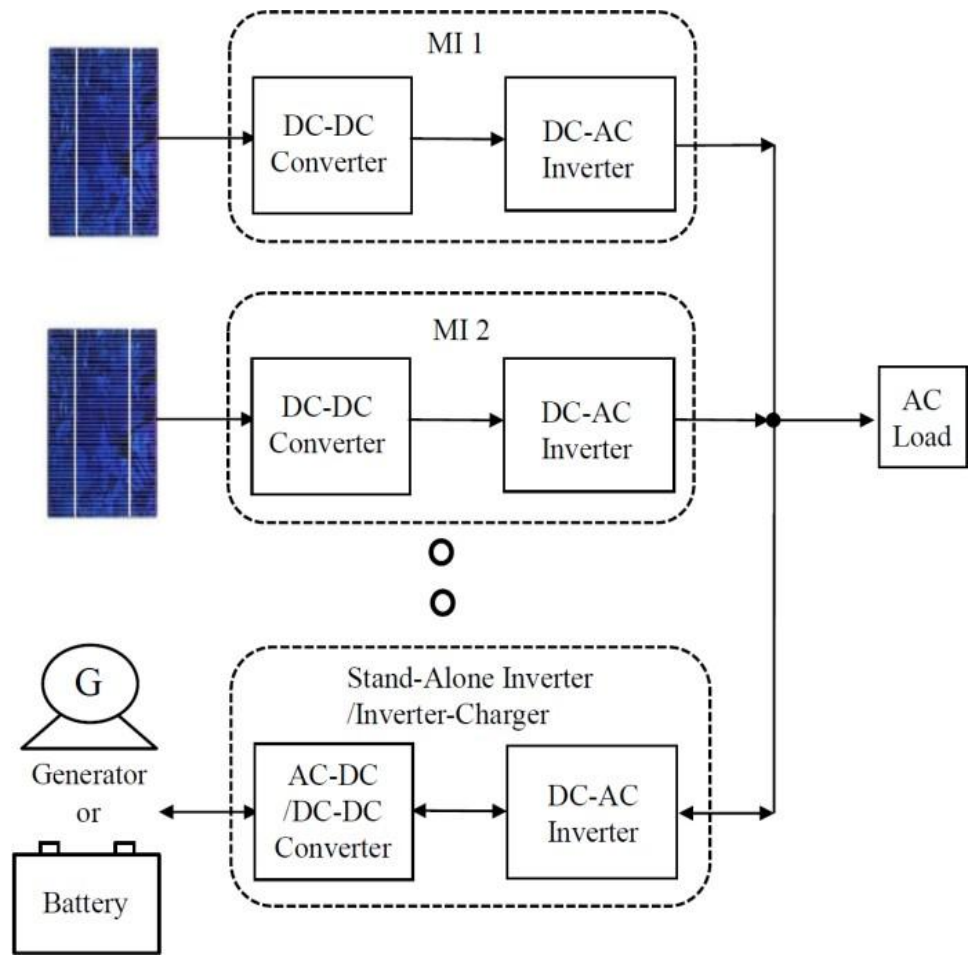


\section{International Journal of Innovative Research in Electrical, Electronics, Instrumentation and Control Engineering}

\section{Vol. 7, Issue 5, May 2019}

A type of technology similar to a micro inverter is a power optimizer which also does panel-level maximum power point tracking, but does not convert to AC per module. Multiple MIs are commonly employed in the construction of larger PV generation systems for grid-connected applications. This situation does not involve the problem of current sharing because current is controlled independently by the MIs based on its own MPPT. In stand-alone mode and LineInteractive Mode (LIM), current sharing is required to deal with fluctuations in PV power, variations in load power, and the need to regulate output voltage. This control problem is highly complex, particularly when devising a system that does not reply on communication or control interconnections between modules. Despite the large number of current sharing control methods that have been devised for stand-alone inverters, no existing system is able to handle current sharing with a PV input source while maintaining the ability to operate in SAM as well as LIM. The proposed Multi inverter employees two-stage topology with active- calmped current-fed push-pull converter cascaded with a fullbridge inverter. The proposed control scheme uses multi loop control to adapt to variations in PV power, load power and grid voltage in conjunction with MPPT to feed available PV power to the grid while in GCM.

\section{PROPOSED SYSTEM}

The proposed control scheme include multi-module control capability with cascaded connections of multiple MI modules between the grid and load. Islanding mode is this project. If the fault occurs on the grid the grid will get disconnected for the main source to protect from damage. Each MI treats its downstream (load-side) MI as a part of its load. Downstream MIs are automatically given priority over up stream (grid-side). MI in the exporting of power. This project implement a partial power converter for DC-DC converter stage.

Aphase-lock-loop (PLL) circuit and an islanding detection circuit are used to detect the grid voltage and generate the synchronous signal. When the grid voltage is normal, the synchronous switch (SS) is kept closed in connecting the inverter to the grid, and the MI operates in GCM or LIM. If the MI is set to operatein GCM. The outer loop is a voltage controller that uses the instantaneous tracking of $\mathrm{AC}$ voltage waveforms to regulate the inverter voltage. A root mean square (RMS) voltage controller is added to correct the voltage amplitude command in order to achieve precise regulation of the voltage. In the event that the load power exceeds the available PV power, the DC-DC converter is unable to regulate the DC bus voltage.

In addition to soft switching of the main switches, the active-clamped circuit shown in enables the DC-DC converter to operate in boost mode (dutyD>0.5)as well as buck mode $(\mathrm{D}<=0.5)$ to enable operation under a wider range of input voltages [23]. In boost mode and buck mode, the voltage conversion can be expressed. As with buck and boost converters, maximum efficiency occurred at the maximum duty in buck mode and the minimum duty in boost mode, i.e., at the boundary between boost mode and buck mode with $D=0.5$.

The current command is generated from the voltage control loop. The control signals for feedback and forward control, respectively. Variations in output voltage cause disturbance in the current loop. The sensed load currents is used as a feed forward control signal to reduce the effects of the load currents on the voltage control loop. The regulated results of the RMS controller is used. To correct the amplitude of the voltage command using a proportional gain control is employed for the voltage controller. The AC coupling converter uses the load current and grid voltage to calculate the fundamental amplitude of load current. The power generated by the current amplitude command generated in the MPPT control loop. The inverter output current is then determined by the results of MPPT. However, if the power generated by the PV module exceeds the load power, then it is less than the current amplitude command generated in the MPPT control loop. The resulting inverter output current is limited by the actual load power to prevent feeding power to the grid. The MPPT controller then deviates from the maximum power point (MPP) of the PV module automatically, and the operating point is determined by the load.

The MPPT and PV voltage control loop the MPPT is executed by the inverter and the DC bus voltage is regulated by the DC-DC converter. As long as the MPPT speed is slower than that of the DC bus voltage control loop. The DC bus voltage will appear to be constant the PV voltage control loop can be modeled. The cascaded connection of multiple MIs (Fig. 2) provides current sharing capability without the need for control interconnections or communication among the MIs. Figures 8 and 9, which involve three MI modules, illustrate the current sharing control systems in LIM and SAM respectively. That GCM is free from the problem of parallel control. Moreover, in the cascaded connection. The load-side of MI 1 is connected to the grid-side of MI 2, the load-side of MI 2 is connected to the grid-side of MI 3, and the load-side of MI 3 is connected to the load. The following MI is treated as the load on current MI. Current sharing in LIM under various load conditions, in which all MI modules are preset to operate in LIM. The design of the AC coupling controller for LIM determines the MI output power based on the minimum PV power and load power. If the load power exceeds the PV power, then MI outputs power equal to PV power through the MPPT controller. 


\title{
International Journal of Innovative Research in Electrical, Electronics, Instrumentation and Control Engineering
}

\author{
Vol. 7, Issue 5, May 2019
}

If the load power is less than the PV power, then MI outputs power in response to the load power, and the operation point of the PV module is shifted away from the maximum power point to the point equal to the load power. The relationship between the power consumed by the load and the power output by the PV modules can be divided into four conditions. under ultra-heavy load power, the power consumed by the load greatly exceeds all of the power generated by PV modules, such that MI 1, MI 2,and MI 3 remain at MPP. The power that cannot be supplied by the PV modules to supply the load is automatically. The power consumed by the load greatly exceeds all of the power generated by PV modules, such that MI 1, MI 2,and MI 3 remain at MPP. The power that cannot be supplied by the PV modules to supply the load is automatically drawn from the grid.

In the heavy load power conditions the consumed power of the load is more than the available power generated by all these PV modules but is larger than the available power generated by PV module 2 and module 3. Therefore, MI 2 and MI 3 will stay at the MPP; however, MI 1 will deviate from the MPP(off MPP) to achieve power balance between the load and PV modules. As a result, there is not surplus real power feeding to the grid. In stand-alone applications or grid-connected applications in which the grid voltage is abnormal, the operating modes of the MIs are as follows: MI 1 in SAM, MI 2 in LIM, and MI 3 in LIM. This makes it possible for the parallel system to regulate the load voltage and supply load power as long as the total power from the PV module exceeds the power required for the load. As shown in Fig. 9(a), under heavy-load conditions, the power required for the load is less than that generated by all three of the PVmodules, but larger than that generated by PV modulus.

\section{SIMULATED AND EXPERIMENT RESULT}

Two examples are conducted to evaluate the efficacy of the proposed method. The rated output power of each MI module wassetto250W.Theparametersofthecomponentsusedinthe circuit are listed in TableII.

Before building an actual circuit, the configuration shown in Fig. 8 is simulated in Power environment to ensure the correctness of the proposed method, the results of which are presented in Fig. 10. The MPP PV module is set at $240 \mathrm{~W}$ with voltage of $30 \mathrm{~V}$ and current of $8 \mathrm{~A}$. The open voltage of the PV module is $38 \mathrm{~V}$ and the short circuit current is $9 \mathrm{~A}$. In this example, the initial $200 \mathrm{~W}$ light load changes to a $600 \mathrm{~W}$ heavy load at $250 \mathrm{~ms}$. In other words, MI 3 provides the initial power to the load with MI 1 and MI 2 providing zero load power until $t=250 \mathrm{~ms}$. The MPP PV module is set at $240 \mathrm{~W}$ with voltage of $30 \mathrm{~V}$ and current of $8 \mathrm{~A}$. The open voltage of the PV module is $38 \mathrm{~V}$ and the short circuit current is 9A. In this example, the initial $200 \mathrm{~W}$ light load changes to a $600 \mathrm{~W}$ heavy load at $250 \mathrm{~ms}$. In other words, MI 3 provides the initial power to the load with MI 1 and MI 2 providing zero load power until $t=250 \mathrm{~ms}$.

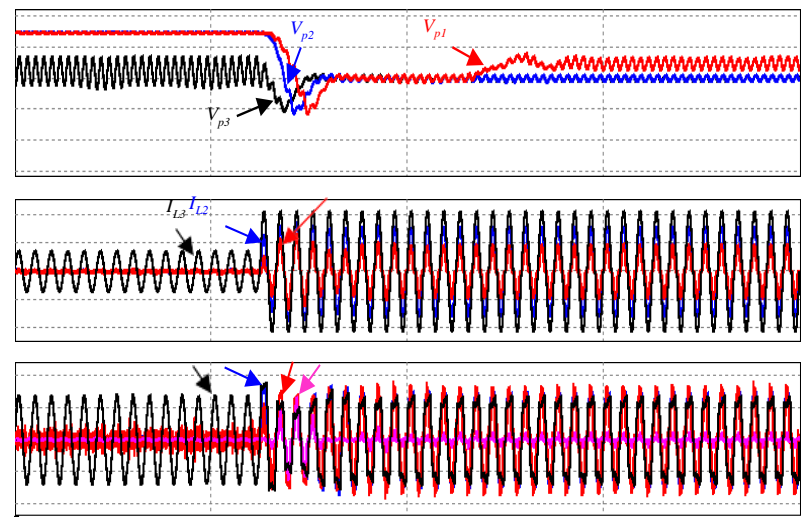

MI 1 and MI 2 do not provide load power before $t=250 \mathrm{~ms}$. Thus, the PV modules of MI 1 and MI 2 are in open voltage condition and the grid power is zero. After $\mathrm{t}=250 \mathrm{~ms}$. The inverter output voltage $V_{O}$ and its RMS value. These results prove that the proposed method satisfies the requirements of SAM in providing good voltage regulation and automatic current sharing.

The proposed 250W MIs were fabricated in accordance with the circuit parameters listed. The control scheme was implemented using the TI DSP F28335. A 5A rating current sensor (HX-05) was used to sense the inductor current $\left(I_{o}\right)$ $\&$ A25A rating current sensor (HX-25)was used to sense the load current $\left(I_{L}\right)$. Thus, the maximum number of parallel modules was limited to 5. We employed a Chroma $62100 \mathrm{H}-600 \mathrm{~S}$ DC power source to emulate the $250 \mathrm{WPV}$ module with MPP setat $(30 \mathrm{~V}, 8.3 \mathrm{~A})$. Figure 12 presents measured efficiency of the proposed MI, which reached a maximum of $92.8 \%$. 


\title{
IJIREEICE
}

\section{International Journal of Innovative Research in Electrical, Electronics, Instrumentation and Control Engineering}

\author{
Vol. 7, Issue 5, May 2019
}

The results obtained under heavy load conditions in LIM. where a 200w light load changed to a 600w heavy load. For the initial 200w light load, only MI3 has to provide power to the load. After changing to 600w heavy load,MI3 and MI2 supply peak PV power, and MI1 supplies only partial PV power. The currents of the output side of MI3. Where the load is $200 \mathrm{w}, \mathrm{MI} 3$ output currents and the load currents are the same. When the load is changed to 600w,MI3 output currents cannot fully supply the load currents.

\section{CONCLUSION}

This paper presents a novel control method for PV MI with three distinct technologies: (i) provision of multifunctionality to extend the application of PVM Ito any power supply system with or without grid support without the need for additional external control devices; (ii) zero-feeding power at grid-connected condition; (iii) multi-module parallel operation of PV MIs without communication and control interconnection at fluctuated PV source and load. In this paper, the configuration of the circuits and functions of the proposed MI were described first. Then, the multimodule parallel control method in LIM and SAM were presented in detail. In addition, the effectiveness of the proposed methods were proven by simulation as well as experimentation. The proposed technique could be applied to any converter or micro grid system with renewable input source in order to extend the power capacity and improve system reliability.

\section{REFERENCES}

[1]. D. M. Scholten, N. Ertugrul, and W. L. Soong, "Micro-inverters in small scale PV systems: A review and future directions," in Power Engineering Conf. (AUPEC), 2013 Australasian Universities, pp. 1-6,2013.

[2]. S. M. Chen, T. J. Liang, L. S. Yang, and J. F. Chen, "A boost converter with capacitor multiplier and coupled inductor for AC module applications," IEEE Trans. Ind. Electron., vol. 60, on. 4, pp. 1503-1511, 2013.

[3]. M. Cespedes, and J. Sun, "Impedance modeling and analysis of grid-connectedvoltage-sourceconverters,"IEEETrans.PowerElectron., vol. 29, no. 3, pp. 1254-1261,2014.

[4]. P. R. Prasanna, and A. K. Rathore, "Analysis, design, and experimental results of a novel soft-Switching snubberless current-fed half-bridge front-end converter-based PV inverter," IEEE Trans. Power Electron., vol. 28, no. 7, pp. 3219-3230,2013.

[5]. A. Kulkarni, and V. John, "Mitigation of lower order harmonics in a grid-connected single-phase PV inverter," IEEE Trans. Power Electron., vol. 28, no. 11, pp. 5024-5037,2013.

[6]. Z.Sinan, F.Deveci, and M.Boztepe, "Volt-second-based control method for discontinuous conduction mode flyback micro-inverters to improve total harmonic distortion," IET Proc. Power Electron., vol. 6, no. 7, pp. 1600-1607,2013.

[7]. S. Daher, J. Schmid, and F. L. M. Antunes, "Multilevel inverter topologies for stand-alone PV systems," IEEE Trans. Ind. Electron., vol. 55, no. 7, pp. 2703-2712,2008.

[8]. J. Minsoo, and V. G. Agelidis, "A boost-inverter-based, battery-supported, fuel-cell sourced three-phase stand-alone power supply," IEEE Trans. Power Electron., vol. 29, no. 12, pp. 6472-6480, 2014.

[9]. Zeke Yewdall, "AC Coupling - Methods," in Issue 162, August/September, 2014, https://www.homepower.com/articles/solarelectricity/design-installation/ac-coupling-methods.

[10]. Dr.K.Dhayalini, S.A.Priyadarshini, "Â MEMS multisensory based intelligent damage detection for wind turbines", International Journal of computer and mathematical sciences, Volume 6, Issue 11, pp.181-189.

[11]. S.A.Priyadarshini, A.Prabhu, "Design of Electrical System Using Mi Power on Load Flow and Stability Analysis", Imperial journal of Interdisciplinary research", Volume 3, Issue 12. 